\title{
The Impact of Non-Ophthalmic Factors on Intravitreal Injections During the COVID-19 Lockdown
}

\author{
Sahar Ashrafzadeh (D) \\ Bradley S Gundlach' \\ Irena Tsui ${ }^{2-4}$ \\ 'David Geffen School of Medicine, \\ University of California, Los Angeles, CA, \\ USA; ${ }^{2}$ Ophthalmology Department, West \\ Los Angeles Veterans Health \\ Administration, Los Angeles, CA, USA; \\ ${ }^{3}$ Retina Division, Stein Eye Institute, \\ University of California, Los Angeles, CA, \\ USA; ${ }^{4}$ Doheny Eye Institute, University of \\ California, Los Angeles, CA, USA
}

Correspondence: Irena Tsui

Tel + I 310 825-7290

Fax + I 310 825-9946

Email itsui@jsei.ucla.edu
Purpose: Early on in the COVID-19 pandemic, it was difficult to know what factors would affect patient and physician decision-making regarding ophthalmic care utilization. The purpose of this study is to investigate the effect of non-ophthalmic factors on patient decision-making to receive intravitreal injections during the COVID-19 lockdown.

Patients and Methods: Data on patients who had intravitreal injection appointments at a tertiary care Veterans Health Administration clinic during a seven-week period (March 19, 2020-May 8, 2020) of the COVID-19 outbreak in Los Angeles County were collected and compared to patients who had intravitreal injection appointments during the same time period in 2019. Demographic characteristics, injection diagnoses, visual acuities, body mass indices, co-morbidities, and psychiatric conditions of patients and clinic volumes were tabulated and compared between the two time periods.

Results: There were 86 patients in the injection clinic in 2020 compared to 176 patients in 2019. The mean age and gender of patients in the injection clinic did not differ between 2019 and 2020. Compared to 2019, the number of patients who identified as Hispanic or Latino remained nearly the same, but the number of patients who identified as White, Black, or Asian or Pacific Islander decreased by nearly half. In 2020, a greater proportion of patients came to the injection clinic for neovascular age-related macular degeneration $(56.5 \%$ vs $39.3 \%, \mathrm{p}=0.017)$, but a decreased proportion of patients diagnosed with a heart condition (OR $0.57,95 \%$ CI $0.33,0.96$ ), chronic obstructive pulmonary disease (OR $0.43,95 \%$ CI $0.21,0.91$ ), or asthma (OR $0.09,95 \%$ CI $0.01,0.70$ ) came to the injection clinic.

Conclusion: The COVID-19 pandemic was associated with behavioral changes in eyecare utilization influenced by race and systemic co-morbidities. These data can be used to design and implement strategies to address disparities in essential ophthalmic care among vulnerable populations.

Keywords: anti-vascular endothelial growth factor, co-morbidities, coronavirus disease 2019, disparities, neovascular age-related macular degeneration, retina

\section{Introduction}

Ophthalmology was one of the most affected sub-specialties during the COVID-19 lockdown period, with a similar reduction in ambulatory clinic regardless of clinic size. ${ }^{1}$ To continue patient care during this time, clinics adopted symptom screening before appointments, universal masking, and rigorous disinfection protocols in between patients. $^{2-4}$ Still, it was difficult to predict how patients and physicians would weigh the risks and benefits of continuing eyecare during the lockdown period. 
Intravitreal injections are the most commonly performed ophthalmic procedure, and regularly timed receipt of injections of anti-vascular endothelial growth factor (anti-VEGF) is an effective, first-line therapy for a variety of retinal diseases, such as neovascular agerelated macular degeneration (nvAMD) and diabetic retinopathy. ${ }^{5}$ Determining the need and urgency of intravitreal injections generally requires an eye exam and optical coherence tomography, ${ }^{6}$ making telemedicine during COVID-19 a poor replacement for in-person evaluation. Reports have already shown that missed injections during COVID-19 have resulted in more submacular hemorrhages, which can cause significant visual loss. ${ }^{7,8}$

While multiple studies around the world have described the decrease in intravitreal injections during early COVID-19 lockdown periods, ${ }^{5,9-19}$ they have primarily focused on ophthalmic factors that affected decision-making. The purpose of this study is to investigate the effect of non-ophthalmic factors on patient decisionmaking to receive intravitreal injections during the COVID-19 lockdown.

\section{Materials and Methods}

This study was approved by the Institutional Review Board (IRB) of the Greater Los Angeles Veterans Health Administration (VHA). The veteran population is considered a vulnerable population due to increasing minority composition. ${ }^{20}$ Patient consent to review medical records was waived by the IRB given the retrospective nature of this study. Confidentiality of patient data was maintained, and this study is compliant with the Declaration of Helsinki. We conducted a retrospective cohort study of all patients who had appointments at the West Los Angeles Veterans Affairs injection clinic during the Los Angeles County lockdown period between March 19, 2020 and May 8, 2020. During this time period, clinic appointments were reviewed a week in advance. If there was decreased vision or any new complaint, patients were encouraged to come in. In addition, patients with the diagnosis of nvAMD and patients with monocular status were encouraged to come in. Patients with stable vision and other diagnoses (ie diabetic macular edema, retinal vein occlusion, and central serous retinopathy) were encouraged to reschedule their appointment. No appointment was canceled if the patient wanted to come in for their appointment regardless of diagnosis or vision. Patients who had injection appointments during the same period in 2019 (March 19, 2019 to May 8, 2019) were identified and used as the comparator group.

We used the VHA Computerized Patient Record System to review electronic medical records in order to collect data on patients' demographics (eg age, gender, self-reported race, and zip code), ophthalmic conditions (eg ophthalmic diagnoses and visual acuities), and non-ophthalmic conditions (eg body mass index [BMI], hypertension, high-risk COVID-19 co-morbidities, and psychiatric conditions).

Medical conditions that were considered high-risk COVID-19 co-morbidities by the Center for Disease Control and Prevention were recorded; these conditions included cancer, chronic kidney disease, chronic obstructive pulmonary disease, heart conditions (defined as heart failure, coronary artery disease, cardiomyopathies, arrhythmias, or valvular insufficiencies), high BMI $\left(>25 \mathrm{~kg} / \mathrm{m}^{2}\right)$, and type 2 diabetes. ${ }^{21}$ Data on patients' psychiatric conditions, which have a higher prevalence among veterans than in the general population, were also recorded from electronic medical records. ${ }^{22}$

The numbers of patients seen in 2019 and 2020 were tabulated and stratified by demographic variables, ophthalmic variables, and non-ophthalmic co-morbidities. Patient distance to the injection clinic was estimated using a home zip code and an online trip calculator (Google Maps) and provided in miles. Odds ratios and Fisher's exact test (used for small sample sizes) were calculated to identify the association between various categorical variables and attendance in the injection clinic. Intravitreal injection acceptance rates among clinic patients with different highrisk co-morbidities during COVID-19 and before COVID19 were assessed with a Chi-square test. The independent samples $t$-test was calculated for continuous variables. The study data were managed using Research Electronic Data Capture (REDCap, Vanderbilt University, Nashville, $\mathrm{TN}),{ }^{23}$ and all data analysis was performed using SPSS (IBM, Armonk, NY). ${ }^{24}$

\section{Results}

The study sample included 262 patients (Table 1), of which 176 patients came to the VHA injection clinic between March 19, 2019 and May 8, 2019 and 86 patients came to the VHA injection clinic between March 19, 2020 and May 8, 2020, a decrease of $51.1 \%$ in clinic volume. The mean age of patients seen in the clinic was 73.8 years in 2019 and 72.0 years in 2020 ( $\mathrm{p}=0.25$ ), and the majority of patients were male $(97.2 \%$ in 2019 vs $95.3 \%$ in 2020 , $\mathrm{p}=0.48$ ). The mean estimated patient distance to the 
Table I Demographics of Patients in Intravitreal Injection Clinic

\begin{tabular}{|c|c|c|c|c|}
\hline & Before COVID-19 a $(N=176)$ & During COVID-19 ${ }^{b}(N=86)$ & OR $(95 \% \mathrm{Cl})^{c}$ & P-value \\
\hline \multicolumn{5}{|l|}{ Gender } \\
\hline Male & |7| (97.2\%) & $82(95.3 \%)$ & $\mathrm{N} / \mathrm{A}$ & 0.48 \\
\hline Female & $5(2.8 \%)$ & 4 (4.7\%) & $\mathrm{N} / \mathrm{A}$ & \\
\hline Age, mean (SD), years & $73.8(1 \mathrm{I} .4)$ & $72.0(11.8)$ & $\mathrm{N} / \mathrm{A}$ & 0.25 \\
\hline \multicolumn{5}{|l|}{ Race $^{d}$} \\
\hline White & $95(54.0 \%)$ & $42(48.8 \%)$ & $0.81(0.49,1.36)$ & 0.43 \\
\hline Black & $34(19.3 \%)$ & 17 (19.8\%) & $1.03(0.54,1.97)$ & 0.93 \\
\hline Hispanic or Latino & $23(13.1 \%)$ & $22(25.5 \%)$ & $2.29(1.19,4.39)$ & $0.012^{*}$ \\
\hline Asian or Pacific Islander & II (6.2\%) & 4 (4.7\%) & $0.73(0.23,2.37)$ & 0.78 \\
\hline American Indian or Alaska Native & $3(1.7 \%)$ & $2(2.3 \%)$ & $1.37(0.23,8.37)$ & 0.66 \\
\hline Other/Unknown & 15 (8.5\%) & $2(2.3 \%)$ & $0.26(0.06,1.14)$ & 0.06 \\
\hline Patient distance to clinic (SD), miles & $38.1(33.4)$ & $34.7(28.2)$ & N/A & 0.42 \\
\hline
\end{tabular}

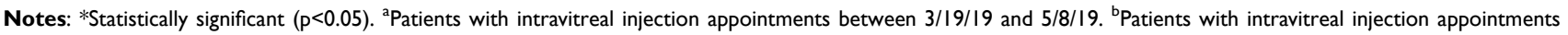
during the COVID-19 pandemic between $3 / 19 / 20$ and 5/8/20. ${ }^{\circ}$ The odds ratio compares the proportion of patients with various characteristics between the two studied time periods (ie during COVID-19 compared to before COVID-19). 'Some patients identified as more than one race.

Abbreviations: SD, Standard deviation; OR, Odds ratio; $\mathrm{Cl}$, Confidence interval.

injection clinic was similar between both years (38.1 miles in 2019 vs 34.7 miles in $2020, p=0.42$ ). The proportion of Hispanic or Latino patients who came to the injection clinic nearly doubled in 2020 compared to 2019 (25.5\% vs $13.1 \%$, OR $2.29,95 \%$ CI $1.19,4.39)$. However, the absolute number of Hispanic or Latino patients in the injection clinic in 2019 and 2020 was nearly equivalent (23 vs 22 patients). In contrast, the proportion of White, Black, and Asian or Pacific Islander patients in the injection clinic remained similar in 2020, but the absolute number of White, Black, and Asian or Pacific Islander patients who came to the injection clinic decreased (White patients: 95 vs 42 patients, Black patients: 34 vs 17 patients, Asian or Pacific Islander patients: 11 vs 4 patients). A Chi-square test of Hispanic vs non-Hispanic ethnicity verified that significantly fewer non-Hispanic patients came to the injection clinic during the COVID19 outbreak $(\mathrm{p}=0.01)$.

The most common diagnoses for which patients received intravitreal injections were nvAMD, diabetic retinopathy, retinal vein occlusion, and central serous chorioretinopathy/pachychoroid with signs of choroidal neovascularization (Table 2). In 2020, a greater proportion of patients came to the injection clinic for nvAMD compared to 2019 (56.5\% vs $39.3 \%$, OR $2.01,95 \%$ CI 1.13 , 3.57). Similar rates of nvAMD were present in both Hispanic and non-Hispanic patients. The proportion of patients with the other ophthalmic diagnoses did not differ significantly, although only approximately one-third of the number of patients with other ophthalmic diagnoses came to injection clinic in 2020 compared to 2019. Visual acuity among patients who came to the injection clinic did not differ between the two time periods.

The prevalence of co-morbidities and psychiatric conditions in patients who came to the injection clinic in 2019 and 2020 are provided in Table 3. The mean BMI of patients who came to the clinic in 2019 and 2020 were similar $\left(28.4 \mathrm{~kg} / \mathrm{m}^{2}\right.$ vs $\left.29.4 \mathrm{~kg} / \mathrm{m}^{2}, \mathrm{p}=0.12\right)$. In 2020, a decreased proportion of patients came to the injection clinic with an existing diagnosis of a heart condition (OR $0.57,95 \%$ CI $0.33,0.96$ ), chronic obstructive pulmonary disease (OR $0.43,95 \%$ CI 0.21 , 0.91 ), or asthma (OR $0.09,95 \%$ CI $0.01,0.70$ ). The proportion of patients with hypertension, type 2 diabetes mellitus, chronic kidney disease, and cancer was similar between both years (all $\mathrm{p}>0.05$ ). Among patients who came to the injection clinic, there were no differences in injection acceptance rates between years when patients were stratified by co-morbidity (all $\mathrm{p}>0.05$ ). Rates of depression (OR $0.81,95 \%$ CI $0.41,1.61$ ), post-traumatic stress disorder (OR 1.09, 95\% CI 0.48, 2.45), anxiety (OR 0.71, 95\% CI 0.25, 2.05), and schizophrenia (OR $0.68,95 \%$ CI $0.13,3.43)$ did not differ between the two time periods.

\section{Discussion}

Decision-making during COVID-19 was particularly complex and challenging with multiple factors being weighed 
Table 2 Ophthalmic Data of Patients in Intravitreal Injection Clinic

\begin{tabular}{|c|c|c|c|c|}
\hline Characteristic & $\begin{array}{l}\text { Before COVID-19 } \\
(\mathrm{N}=176)\end{array}$ & $\begin{array}{l}\text { During COVID-19 } \\
(\mathrm{N}=86)\end{array}$ & OR $(95 \% \mathrm{Cl})^{c}$ & P-value \\
\hline Patients receiving an injection & $150(85.2 \%)$ & $69(80.2 \%)$ & $0.70(0.36,1.38)$ & 0.31 \\
\hline \multicolumn{5}{|l|}{ Injection diagnosis ${ }^{d}$} \\
\hline Age-related macular degeneration & $59(39.3 \%)$ & 39 (56.5\%) & $2.01(1.13,3.57)$ & $0.017 *$ \\
\hline $\begin{array}{l}\text { Diabetic retinopathy, diabetic macular edema, and/ } \\
\text { or neovascularization }\end{array}$ & $53(35.3 \%)$ & $19(27.5 \%)$ & $0.66(0.36,1.20)$ & 0.25 \\
\hline $\begin{array}{l}\text { Retinal vein occlusion macular edema and/or } \\
\text { neovascularization }\end{array}$ & $26(17.3 \%)$ & $9(13.0 \%)$ & $0.67(0.30, \mathrm{I} .5 \mathrm{I})$ & 0.42 \\
\hline Central serous retinopathy/pachychoroid with CNV & $3(2.0 \%)$ & $\mathrm{I}(\mathrm{I} .4 \%)$ & $0.68(0.07,6.62)$ & 0.99 \\
\hline Other & $9(6.0 \%)$ & $2(2.8 \%)$ & $0.44(0.09,2.09)$ & 0.51 \\
\hline \multicolumn{5}{|l|}{ Visual acuity of injected eye } \\
\hline Better than $20 / 70$ & $64(42.7 \%)$ & $30(43.5 \%)$ & $0.94(0.55, \mathrm{I} .6 \mathrm{I})$ & 0.82 \\
\hline $20 / 70$ to better than $20 / 200$ & $32(21.3 \%)$ & II (I5.9\%) & $0.66(0.31,1.38)$ & 0.27 \\
\hline $20 / 200$ or worse & 54 (36.0\%) & $28(40.8 \%)$ & $1.09(0.63,1.90)$ & 0.76 \\
\hline
\end{tabular}

Notes: *Statistically significant $(p<0.05)$. ${ }^{a}$ Patients with intravitreal injection appointments between $3 / 19 / 19$ and $5 / 8 / 19$. ${ }^{b}$ Patients with intravitreal injection appointments during the COVID-19 pandemic between $3 / 19 / 20$ and 5/8/20. ${ }^{\mathrm{T}}$ The odds ratio compares the proportion of patients with various characteristics between the two studied time periods (ie during COVID-19 compared to before COVID-19). ${ }^{\mathrm{d}} \mathrm{A}$ patient may have more than one injection diagnosis.

Abbreviations: SD, Standard deviation; OR, Odds ratio; Cl, Confidence interval; CNV, Choroidal neovascularization.

and ultimately coming down to the risk of vision loss compared to the risk of contracting or spreading COVID19 for patients seeking eyecare. ${ }^{25}$ While it was difficult for providers to determine which patients would continue to seek eyecare during the COVID-19 lockdown, state and local guidelines were constantly changing. ${ }^{1}$ While we do not know individual decision-making processes that influenced patients and physicians during the lockdown period, we can study who came in and infer what factors influenced behavioral changes during this time.

Prior studies have reported decreases in injection clinic volumes during local COVID-19 lockdown periods ranging from $3.2 \%$ to $98.7 \%$, with most in the $40-60 \%$ range (Table 4). ${ }^{5,9-19}$ An academic center in Italy called all injection patients to reassure them of COVID-19 infection precautions, resulting in only a $3.2 \%$ decrease in clinic volume. ${ }^{13}$ On the other end of the spectrum, an academic center in India reported a $98.7 \%$ decrease in injection clinic volume, which the authors attributed to the shutdown of public transportation and limited hospital infrastructure. ${ }^{19}$ Public transportation continued to run in Los Angeles County during the lockdown, and our hospital did not have infrastructure issues limiting injection clinic volume. Physicians called patients before their appointments and made recommendations based on whether the benefits of injection considering ophthalmic factors (ie nvAMD, monocular, new symptoms) outweighed the risk of contracting COVID-19, ${ }^{26-29}$ but all patients who wanted to keep their appointment were allowed to come in. With this strategy, we saw a $51.1 \%$ decrease in the injection clinic volume, with a greater proportion of patients with nvAMD seeking eyecare during the pandemic. We did not find differences in visual acuities of patients who came into clinic when stratified by categories of low vision $(<20 / 70)$ or legal blindness $(20 /$ $200)$ in the better-seeing eye or in the injection eye. However, two other studies reported having decreased vision in the fellow eye as influencing patients' decisions to return during COVID-19.9,30

Our study found that the number of patients in the injection clinic who identified as Hispanic or Latino remained nearly the same, while the number of patients who identified as non-Hispanic or non-Latino (ie White, Black, Asian or Pacific Islander, American Indian or Alaska Native, and other races) decreased significantly. A large study looking at inpatient hospitalizations across 12 states during COVID-19 found that the Hispanic and Latino community has been disproportionately impacted by COVID-19 hospitalizations in the United States, with reasons including their essential worker status, comorbidities, and multigenerational housing. ${ }^{31}$ We speculate that Hispanic and Latino patients may have been more inclined to keep injection clinic appointments due to their higher likelihood of living in multi-generational housing 
Table 3 Rates of High-Risk Co-Morbidities for COVID-I9 and Psychiatric Conditions

\begin{tabular}{|c|c|c|c|c|}
\hline Characteristic & Before COVID-19 a $(N=176)$ & During COVID-19 ${ }^{b}(N=86)$ & OR $(95 \% \mathrm{Cl})^{c}$ & P-value \\
\hline BMI, mean, $\mathrm{kg} / \mathrm{m}^{2}(\mathrm{SD})$ & $28.4(4.5)$ & $29.4(5.9)$ & N/A & 0.12 \\
\hline Hypertension & $150(85.2 \%)$ & 71 (82.6\%) & $0.82(0.4 \mathrm{I}, \mathrm{I} .64)$ & 0.58 \\
\hline Type 2 diabetes mellitus & 101 (57.4\%) & $50(58.1 \%)$ & $1.03(0.61,1.74)$ & 0.91 \\
\hline Heart conditions $^{c}$ & 81 (46.0\%) & $28(32.6 \%)$ & $0.57(0.33,0.96)$ & $0.038^{*}$ \\
\hline Chronic kidney disease & $43(24.4 \%)$ & 18 (20.9\%) & $0.82(0.44,1.53)$ & 0.53 \\
\hline Chronic obstructive pulmonary disease & $4 \mathrm{I}(23.3 \%)$ & $10(11.6 \%)$ & $0.43(0.21,0.91)$ & $0.025^{*}$ \\
\hline Asthma & $20(11.4 \%)$ & $\mathrm{I}(\mathrm{I} .2 \%)$ & $0.09(0.01,0.70)$ & $0.004 *$ \\
\hline Cancer & II (6.3\%) & $9(10.5 \%)$ & $\mathrm{I} .75(0.70,4.4 \mathrm{I})$ & 0.23 \\
\hline \multicolumn{5}{|l|}{ Psychiatric conditions } \\
\hline Depression & $34(19.3 \%)$ & $14(16.3 \%)$ & $0.8 \mathrm{I}(0.4 \mathrm{I}, \mathrm{I} .6 \mathrm{I})$ & 0.55 \\
\hline Post-traumatic stress disorder & $19(10.8 \%)$ & $10(11.6 \%)$ & $1.09(0.48,2.45)$ & 0.84 \\
\hline Anxiety & 14 (8.0\%) & $5(5.8 \%)$ & $0.7 \mathrm{I}(0.25,2.05)$ & 0.53 \\
\hline Schizophrenia & $6(3.4 \%)$ & $2(2.3 \%)$ & $0.68(0.13,3.43)$ & 0.99 \\
\hline
\end{tabular}

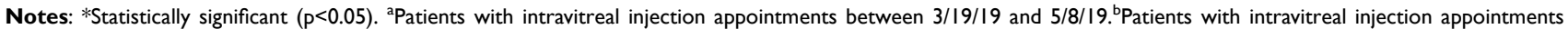
during the COVID- 19 pandemic between $3 / 19 / 20$ and 5/8/20. ${ }^{\circ}$ The odds ratio compares the proportion of patients with various characteristics between the two studied

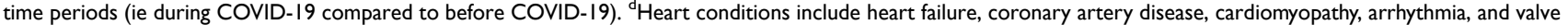
insufficiencies.

Abbreviations: SD, Standard deviation; OR, Odds ratio; $\mathrm{Cl}$, Confidence interval; BMI, Body mass index.

and having essential worker status, which would make the decision to receive eyecare of minimal additional increased risk of COVID-19 exposure. ${ }^{32}$ While language barriers may have affected patient decision-making during the COVID-19 pandemic in some clinical settings, our injection clinic did not routinely encounter language barriers since English proficiency is a requirement for enlisting in the military. ${ }^{33}$

In addition, we found that patients with cardiac and pulmonary risk factors (ie heart conditions, chronic obstructive pulmonary disease, and asthma) were significantly less likely to come to the injection clinic during the lockdown period. One intravitreal injection clinic specifically studied patients who did not receive injections during COVID-19 and reported that patients' fear of contracting COVID-19 was a leading cause of disrupted injection schedules during the pandemic. ${ }^{34}$ Furthermore, delay in seeking healthcare due to high-risk COVID-19 comorbidities has been shown outside the field of ophthalmology due to the fear of contracting COVID-19 from the hospital. ${ }^{35-38}$ Therefore, it makes sense that increased risk of morbidity and mortality among patients with cardiac and pulmonary diseases may have made patients less likely to come in for an eye injection. COVID-19 has also had a large mental health impact by contributing to increased anxiety and depression and concurrent difficulty in accessing mental healthcare among vulnerable populations. ${ }^{39}$ The veteran population has a high prevalence of mental health disorders, such as depression and post-traumatic stress disorder, ${ }^{22}$ and we found no difference in rates of psychiatric co-morbidities influencing the decision to return for eye injections during the lockdown period.

The strengths of this study include its examination of an underserved and racially diverse veteran population and consideration of systemic co-morbidities with regard to medical decision-making during the COVID-19 lockdown. This study was limited by its use of a single institution database, predominantly male patient population, and lack of data on patients who did not show up for clinic appointments. Nonetheless, we were able to leverage a patient population that almost exclusively receives all medical care from one institution with a single medical record system, making data collection on co-morbidities and psychiatric history more accessible, accurate, and comprehensive compared to relying on patient self-reporting or outside medical records.

\section{Conclusion}

In summary, we found differences in race and high-risk co-morbidities among veteran patients who returned for intravitreal injection clinic appointments during the early lockdown period of COVID-19 in 2020 compared to the same time period in 2019. This study highlights the decision-making differences leading to decreased injections among non-Hispanic veteran patients as well as 
Table 4 Studies Reporting on Changes in Intravitreal Injection Clinic Volumes During the COVID-19 Lockdown

\begin{tabular}{|c|c|c|c|c|c|c|c|}
\hline $\begin{array}{l}\text { Lockdown } \\
\text { Time Period } \\
(2020)\end{array}$ & Country & Center(s) & $N(2020)$ & $N(20 \mid 9)$ & $\begin{array}{l}\text { \% Change in } \\
\text { Clinic } \\
\text { Volume }\end{array}$ & $\begin{array}{l}\text { Ophthalmic } \\
\text { Factors in } 2020\end{array}$ & $\begin{array}{l}\text { Non-Ophthalmic Factors } \\
\text { in } 2020\end{array}$ \\
\hline$|/ 2|-6 / \mid$ & China & I Academic ${ }^{9}$ & 93 & 307 & -69.7 & $\begin{array}{l}\text { Worsened BCVA; } \\
\text { Increased CRT }\end{array}$ & \\
\hline $3 /|-5 / 3|$ & Italy & I Academic ${ }^{40}$ & 40 & 483 & -91.7 & $\begin{array}{l}\text { Relative increase } \\
\text { in corticosteroid } \\
\text { treatment }\end{array}$ & \\
\hline $3 / 2-5 / 31$ & $\begin{array}{l}\text { United } \\
\text { States }\end{array}$ & $\begin{array}{l}\text { I2 Academic, } 5 \\
\text { Private }^{11}\end{array}$ & $\begin{array}{l}329 \\
\text { (weekly) }\end{array}$ & $\begin{array}{l}425 \\
\text { (weekly) }\end{array}$ & -22.6 & & \\
\hline $3 / 9-4 / 30$ & Italy & I Academic ${ }^{13}$ & 91 & 94 & $-3.2 \%$ & & \\
\hline $3 / 9-5 / 3$ & Italy & I Academic ${ }^{12}$ & 583 & 1252 & -53.6 & & \\
\hline $3 / 9-5 / 17$ & $\begin{array}{l}\text { United } \\
\text { States }\end{array}$ & 320 Private $^{14}$ & $\begin{array}{l}21,877 \\
\text { (weekly) }\end{array}$ & $\begin{array}{l}25,226 \\
\text { (weekly) }\end{array}$ & -13.3 & & \\
\hline $3 / 10-4 / 9$ & Italy & 6 Academic $^{15}$ & 686 & 1,458 & -52.9 & $\begin{array}{l}\text { Relative increase } \\
\text { in AMD }\end{array}$ & Decrease in mean age \\
\hline $3 / 10-5 / 9$ & Italy & 39 Academic $^{16}$ & 9,751 & 19,646 & -50.4 & $\begin{array}{l}\text { Relative decrease } \\
\text { in corticosteroid } \\
\text { injections; Relative } \\
\text { increase in AMD } \\
\text { and RVO }\end{array}$ & \\
\hline $3 / 15-4 / 14$ & Israel & I Academic ${ }^{5}$ & 636 & 995 & -36.1 & & \\
\hline $3 / 16-5 / 8$ & $\begin{array}{l}\text { United } \\
\text { States }\end{array}$ & $\begin{array}{l}\text { I Academic, } \\
2 \text { Private }^{17}\end{array}$ & $\begin{array}{l}158 \\
\text { (weekly) }\end{array}$ & $\begin{array}{l}292 \\
(\text { weekly })^{a}\end{array}$ & -45.9 & & \\
\hline $3 / 16-5 / 10$ & France & National ${ }^{18}$ & 87,316 & $133,697^{b}$ & -34.7 & $\begin{array}{l}\text { Relative decrease } \\
\text { in new users of } \\
\text { anti-VEGF } \\
\text { injections }\end{array}$ & \\
\hline $\begin{array}{l}\text { 3/19-5/8 } \\
\text { (current } \\
\text { study)c }\end{array}$ & $\begin{array}{l}\text { United } \\
\text { States }\end{array}$ & $\begin{array}{l}\text { I Veterans } \\
\text { Affairs } \\
\text { Medical } \\
\text { Center }\end{array}$ & 86 & 176 & -51.1 & $\begin{array}{l}\text { Relative } \\
\text { increase in } \\
\text { AMD }\end{array}$ & $\begin{array}{l}\text { Relative increase in } \\
\text { Hispanic/Latino race; } \\
\text { Relative decrease in co- } \\
\text { morbidities (heart } \\
\text { disease, COPD, asthma) }\end{array}$ \\
\hline $3 / 25-5 / 3$ & India & I Academic ${ }^{19}$ & 15 & 1160 & -98.7 & & $\begin{array}{l}\text { Decrease in mean age; } \\
\text { Relative increase in women }\end{array}$ \\
\hline
\end{tabular}

Notes: ${ }^{\mathrm{a}}$ Pre-COVID-19 weekly average. ${ }^{\mathrm{b}}$ Expected number of patients was calculated using clinic volumes from 2018, 2019, and early 2020. 'Bold formatting is used to describe the findings of the current study.

Abbreviations: AMD, age-related macular degeneration; anti-VEGF, anti-vascular endothelial growth factor; BCVA, best-corrected visual acuity; CMT, central macular thickness; COPD, chronic obstructive pulmonary disease; CRT, central retinal thickness; RVO, retinal vein occlusion. 
veterans at high risk of severe mortality and morbidity from COVID-19 infection. Ophthalmologists and healthcare systems can use this data to address the concerns of vulnerable populations to ensure patients are receiving safe, timely, and essential ophthalmic care. At this time, we recommend that eye clinics with mandatory staff vaccination and sufficient infection prevention measures prioritize rescheduling patients with high-risk comorbidities for COVID-19 who may have missed appointments during 2020. As COVID-19 continues to persist in countries around the world, further research is needed to investigate the long-term effects of medical decision-making during the COVID-19 pandemic on vision and ophthalmic diseases.

\section{Abbreviations}

BMI, Body mass index; COVID-19, coronavirus disease 2019; IRB, Institutional review board; nvAMD, Neovascular age-related macular degeneration; VEGF, Vascular endothelial growth factor; VHA, Veterans Health Administration.

\section{Disclaimer}

The views expressed in this article are those of the authors and do not necessarily reflect the position or policy of the Department of Veterans Affairs or the United States government.

\section{Funding}

This work is supported by an Unrestricted Grant from Research to Prevent Blindness, Inc. to the Department of Ophthalmology at UCLA.

\section{Disclosure}

The authors report no conflicts of interest in this work.

\section{References}

1. Mehrotra A, Chernew M, Linetsky D, Hatch H, Cutler D. The impact of the COVID-19 pandemic on outpatient visits: a rebound emerges; 2020. Available from: https://www.commonwealthfund.org/publica tions/2020/apr/impact-covid-19-outpatient-visits. Accessed August 5, 2021.

2. Safadi K, Kruger JM, Chowers I, et al. Ophthalmology practice during the COVID-19 pandemic. BMJ Open Ophthalmol. 2020;5(1):e00487. doi:10.1136/bmjophth-2020-000487

3. Agarwal D, Kumar A. Managing intravitreal injections in adults in COVID-19 and post-COVID-19 era- Initial experiences. Indian J Ophthalmol. 2020;68(6):1216-1218. doi:10.4103/ijo.IJO_1391_20

4. Syed AAO, Jahan S, Aldahlaw AA, Alghazzawi EA. Preventive practices of ophthalmologists during COVID-19 pandemic. Clin Ophthalmol. 2021;15:1267-1275. doi:10.2147/OPTH.S295730
5. Wasser LM, Weill Y, Brosh K, et al. The impact of COVID-19 on intravitreal injection compliance. SN Compr Clin Med. 2020;2:1-4. doi:10.1007/s42399-020-00614-4.

6. Mansour SE, Browning DJ, Wong K, Flynn HW, Bhavsar AR. The evolving treatment of diabetic retinopathy. Clin Ophthalmol. 2020;14:653-678. doi:10.2147/OPTH.S236637

7. Romano F, Monteduro D, Airaldi M, et al. Increased number of submacular hemorrhages as a consequence of coronavirus disease 2019 lockdown. Ophthalmol Retina. 2020;4(12):1209-1210. doi:10.1016/j.oret.2020.06.027

8. Ashkenazy N, Goduni L, Smiddy WE. Short-term effects of COVID-19-related deferral of intravitreal injection visits. Clin Ophthalmol. 2021;15:413-417. doi:10.2147/OPTH.S296345

9. Yang KB, Feng H, Zhang H. Effects of the COVID-19 pandemic on anti-vascular endothelial growth factor treatment in China. Front Med. 2020;7:576275. doi:10.3389/fmed.2020.576275

10. Carnevali A, Giannaccare G, Gatti V, Scuteri G, Randazzo G, Scorcia V. Intravitreal injections during COVID-19 outbreak: real-world experience from an Italian tertiary referral center. Eur J Ophthalmol. 2021;31(1):10-12. doi:10.1177/1120672120962032

11. Breazzano MP, Nair AA, Arevalo JF, et al. Frequency of urgent or emergent vitreoretinal surgical procedures in the United States during the COVID-19 pandemic. JAMA Ophthalmol. 2021;139(4):456. doi:10.1001/jamaophthalmol.2021.0036

12. Borrelli E, Grosso D, Vella G, et al. Impact of COVID-19 on outpatient visits and intravitreal treatments in a referral retina unit: let's be ready for a plausible "rebound effect". Graefes Arch Clin Exp Ophthalmol. 2020;258(12):2655-2660. doi:10.1007/s00417-020-04858-7

13. Legrottaglie EF, Balia L, Camesasca FI, et al. Management of an ophthalmology department during COVID-19 pandemic in Milan, Italy. Eur J Ophthalmol. 2020:1120672120960334. doi:10.1177/ 1120672120960334.

14. Xu D, Starr MR, Boucher N, et al. Real-world vitreoretinal practice patterns during the 2020 COVID-19 pandemic: a nationwide, aggregated health record analysis. Curr Opin Ophthalmol. 2020;31 (5):427-434. doi:10.1097/ICU.0000000000000692

15. dell'Omo R, Filippelli M, Semeraro F, et al. Effects of the first month of lockdown for COVID-19 in Italy: a preliminary analysis on the eyecare system from six centers. Eur J Ophthalmol. 2020. doi:10.1177/1120672120953074.

16. dell'Omo R, Filippelli M, Virgili G, et al. Effect of COVID-19related lockdown on ophthalmic practice in Italy: a report from 39 institutional centers. Eur J Ophthalmol. 2021. doi:10.1177/ 11206721211002442 .

17. El Hamichi S, Gold A, Heier J, Kiss S, Murray TG. Impact of the COVID-19 pandemic on essential vitreoretinal care with three epicenters in the United States. Clin Ophthalmol. 2020;14:2593-2598. doi:10.2147/OPTH.S267950

18. Billioti de Gage S, Drouin J, Desplas D, et al. Intravitreal anti-vascular endothelial growth factor use in France during the coronavirus disease 2019 pandemic. JAMA Ophthalmol. 2021;139 (2):240-242. doi:10.1001/jamaophthalmol.2020.5594

19. Babu N, Kohli P, Mishra C, et al. To evaluate the effect of COVID-19 pandemic and national lockdown on patient care at a tertiary-care ophthalmology institute. Indian $J$ Ophthalmol. 2020;68 (8):1540-1544. doi:10.4103/ijo.IJO_1673_20

20. Health Equity. U.S. Department of Veteran Affairs. Available from: https://www.research.va.gov/topics/health_equity.cfm. Accessed May 29, 2021.

21. Available from: https://www.cdc.gov/coronavirus/2019-ncov/needextra-precautions/people-with-medical-conditions.html. Accessed August 5, 2021.

22. Hoerster KD, Lehavot K, Simpson T, McFall M, Reiber G, Nelson KM. Health and health behavior differences: U.S. Military, veteran, and civilian men. Am J Prev Med. 2012;43(5):483-489. doi:10.1016/j.amepre.2012.07.029 
23. Harris PA, Taylor R, Thielke R, Payne J, Gonzalez N, Conde JG. Research electronic data capture (REDCap)-a metadata-driven methodology and workflow process for providing translational research informatics support. $J$ Biomed Inform. 2009;42(2):377-381. doi:10.1016/j.jbi.2008.08.010

24. IBM SPSS Statistics for Windows. Version 27.0. 2020.

25. Lindeke-Myers A, Zhao PYC, Meyer BI, et al. Patient perceptions of SARS-CoV-2 exposure risk and association with continuity of ophthalmic care. JAMA Ophthalmol. 2021;139(5):508. doi:10.1001/ jamaophthalmol.2021.0114

26. Rosenfeld PJ, Brown DM, Heier JS, et al. Ranibizumab for neovascular age-related macular degeneration. $N$ Engl J Med. 2006;355 (14):1419-1431. doi:10.1056/NEJMoa054481

27. Brown DM, Kaiser PK, Michels M, et al. Ranibizumab versus verteporfin for neovascular age-related macular degeneration. $N \mathrm{Engl}$ J Med. 2006;355(14):1432-1444. doi:10.1056/NEJMoa062655

28. Kiss S, Campbell J, Almony A, et al. Management and outcomes for neovascular age-related macular degeneration: analysis of United States electronic health records. Ophthalmology. 2020;127 (9):1179-1188. doi:10.1016/j.ophtha.2020.02.027

29. American Academy of Ophthalmology. Available from: https://www. aao.org/headline/new-recommendations-urgent-nonurgent-patientcare. Accessed April 1, 2021.

30. Viola F, Milella P, Giuffrida FP, Ganci S, Invernizzi A. The impact of coronavirus disease (COVID-19) pandemic on intravitreal injections treatment for macular diseases: report from a referral hospital in Milan. Retina. 2020;41:701-706. doi:10.1097/IAE.0000000000002941

31. Karaca-Mandic P, Georgiou A, Sen S. Assessment of COVID-19 hospitalizations by race/ethnicity in 12 states. JAMA Intern Med. 2020;181:131-134. doi:10.1001/jamainternmed.2020.3857

32. Macias Gil R, Marcelin JR, Zuniga-Blanco B, Marquez C, Mathew T, Piggott DA. COVID-19 pandemic: disparate health impact on the hispanic/latinx population in the United States. J Infect Dis. 2020;222 (10):1592-1595. doi:10.1093/infdis/jiaa474
33. Understanding the ASVAB Test. U.S. army; 2021. Available from: https://www.goarmy.com/learn/understanding-the-asvab.html. Accessed May 25, 2021.

34. Moussa M, Elshorbagy MS, Emarah A, et al. Intravitreal injections of anti-VEGF agents during COVID-19 pandemic: clinical audit from Tanta University Hospital. Int Ophthalmol. 2021;41:1437-1443. doi:10.1007/s10792-021-01719-y

35. Baum A, Schwartz MD. Admissions to veterans affairs hospitals for emergency conditions during the COVID-19 pandemic. JAMA. 2020;324(1):96-99. doi:10.1001/jama.2020.9972

36. Wadhera RK, Shen C, Gondi S, Chen S, Kazi DS, Yeh RW. Cardiovascular deaths during the COVID-19 pandemic in the United States. J Am Coll Cardiol. 2021;77(2):159-169. doi:10.1016/j. jacc.2020.10.055

37. Press VG, Gershon AS, Sciurba FC, Blagev DP. Concerns about coronavirus disease-related collateral damage for patients with COPD. Chest. 2020;158(3):866-868. doi:10.1016/j.chest.2020.05.549

38. Arora N, Lowe D, Sarsour N, et al. Asthma care during COVID-19: differences in attitudes and expectations between physicians and patients. J Asthma. 2021:1-7. doi:10.1080/02770903.2021.1887214.

39. Aragona M, Barbato A, Cavani A, Costanzo G, Mirisola C. Negative impacts of COVID-19 lockdown on mental health service access and follow-up adherence for immigrants and individuals in socio-economic difficulties. Public Health. 2020;186:52-56. doi:10.1016/j. puhe.2020.06.055

40. Carnevali A, Giannaccare G, Gatti V, Scuteri G, Randazzo G, Scorcia V. Intravitreal injections during COVID-19 outbreak: real-world experience from an Italian tertiary referral center. Eur J Ophthalmol. 2020. doi:10.1177/1120672120962032
Clinical Ophthalmology

\section{Publish your work in this journal}

Clinical Ophthalmology is an international, peer-reviewed journal covering all subspecialties within ophthalmology. Key topics include: Optometry; Visual science; Pharmacology and drug therapy in eye diseases; Basic Sciences; Primary and Secondary eye care; Patient Safety and Quality of Care Improvements. This journal is indexed on PubMed

\section{Dovepress}

Central and CAS, and is the official journal of The Society of Clinical Ophthalmology (SCO). The manuscript management system is completely online and includes a very quick and fair peer-review system, which is all easy to use. Visit http://www.dovepress.com/ testimonials.php to read real quotes from published authors. 